\title{
GEORGES PEREC E A INTERMIDIALIDADE: A CRIAÇÃO LITERÁRIA A PARTIR DE IMAGENS
}

\author{
Tatiana Barbosa Cavalari
}

Resumo: $O$ presente trabalho pretende refletir sobre as relações de intermidialidade na criação literária do escritor francês Georges Perec. Entre outros exemplos, a ilustração The art of living, de Saul Steinberg, inspirou um dos seus livros mais importantes, La vie mode d'emploi. O trabalho de parceria com fotógrafos, ilustradores, cineastas, resultou em novas experiências artísticas e, a partir de Barthes, podemos pensar na intermidialidade não mais como uma "redução do texto à imagem", mas sim uma "amplificação de um em relação ao outro".

Palavras-chave: Intermidialidade. Criação Literária. Imagens.

\section{GEORGES PEREC AND INTERMEDIALITY: THE LITERARY CREATION FROM IMAGES}

\begin{abstract}
This paper aims to reflect on the relations of intermediality in the literary creation of Georges Perec. Among other examples, the illustration The art of living, of Saul Steinberg, inspired one of his most important books, La vie mode d' emploi. The partnership with photographers, illustrators, filmmakers, resulted in new artistic experiences and we can think of intermediality, from Barthes, not as a "reduction of the text in the image" but rather an "amplification relative to other".
\end{abstract}

Keywords: Intermediality. Literary Creation. Images.

\section{Como ler as imagens em Perec?}

Georges Perec, escritor francês do século XX (1936-1982), autor célebre por suas obras literárias consideradas “experimentais"1, buscava constantemente relacionar seu trabalho de escritor a outras formas de arte: $o$

\footnotetext{
${ }^{1}$ A característica experimental da escrita de Perec tem maior destaque com sua participação no grupo Oulipo, (Ouvroir de Littérature Potentielle), que tinha como parâmetro seguir determinadas restrições no processo de escrita dos textos literários. Fundado por Raymond Queneau e François Le Lionnais em 1960, reagrupou também escritores de nacionalidades diversas, como Italo Calvino, Harry Matheus, e matemáticos como Claude Berge, escritores-matemáticos como Jacques Roubaud, um historiador e poeta como Marcel Bénabou.
} 
cinema, a pintura, a fotografia, as ilustrações, jogos de palavras, são constantemente interligados ao trabalho de criação literária. A pergunta inicial que se faz, a partir dessas relações, pode ser: o que Perec buscava, quando realizava parcerias com artistas de outras áreas, ou melhor dizendo: qual era o resultado dessas parcerias no seu trabalho de escrita?

O próprio autor questionava-se constantemente sempre sobre como realizar essa tarefa: como trabalhar com outro artista? Em uma conferência realizada na Association culturelle ítalo-française de Bologne, em 1981, Perec reflete sobre seu trabalho numa espécie de retrospectiva, tratando das relações entre seu texto e o trabalho de parceria com outros artistas ${ }^{2}$.

O que ficou evidente nessas parcerias foi um conjunto de acontecimentos diferentes para cada situação: em alguns momentos, artistas procuravam Perec pedindo que escrevesse a respeito de suas gravuras, outras vezes os próprios editores "encomendavam" esses trabalhos. Mas na maioria das vezes ficou evidente que esses trabalhos, apesar de nem sempre serem escolhidos pelo próprio autor, eram considerados verdadeiros desafios para os envolvidos: "a obra gráfica vai funcionar como um desafio para o escritor, ou a obra escrita vai funcionar como um desafio para o pintor" (p. 200).

É como se, a partir da intensa observação das obras gráficas, Perec conseguisse, de certa forma, "traduzir" o trabalho daquele artista em palavras, ou transpor as ideias e imagens para o trabalho literário: "o que eu tento fazer, é fazer com que o que sinto vendo o trabalho de um artista, de um pintor ou de um fotógrafo seja traduzido em algo que faço do ponto de vista do meu próprio trabalho" (p. 196).

Perec vai citar brevemente o trabalho desenvolvido com cada artista: oito gravuras criadas pelo artista italiano Antonio Corpora em conjunto com seus poemas; o livro Alphabets com ilustrações de Dado, (um pintor iugoslavo que vivia na França); ou textos para acompanhar gravuras de Paolo Boni, a partir de desenhos já existentes. Na imagem (Figura 1), temos um dos exemplos desse trabalho: página de Alphabetsilustrada por Dado. ${ }^{3}$

\footnotetext{
2 Conferência transcrita parcialmente sob o título de "Je ne suis absolument pas critique d'art", nos Cahiers Georges Perec 6, p. 196-203. As citações seguintes de Perec referem-se a essa transcrição.

${ }^{3}$ Todas as imagens reproduzidas nesse trabalho fazem parte do livro Georges Perec Images, de Jacques Neefs e Hans Hartje, Éd. Seuil, 1993.
} 


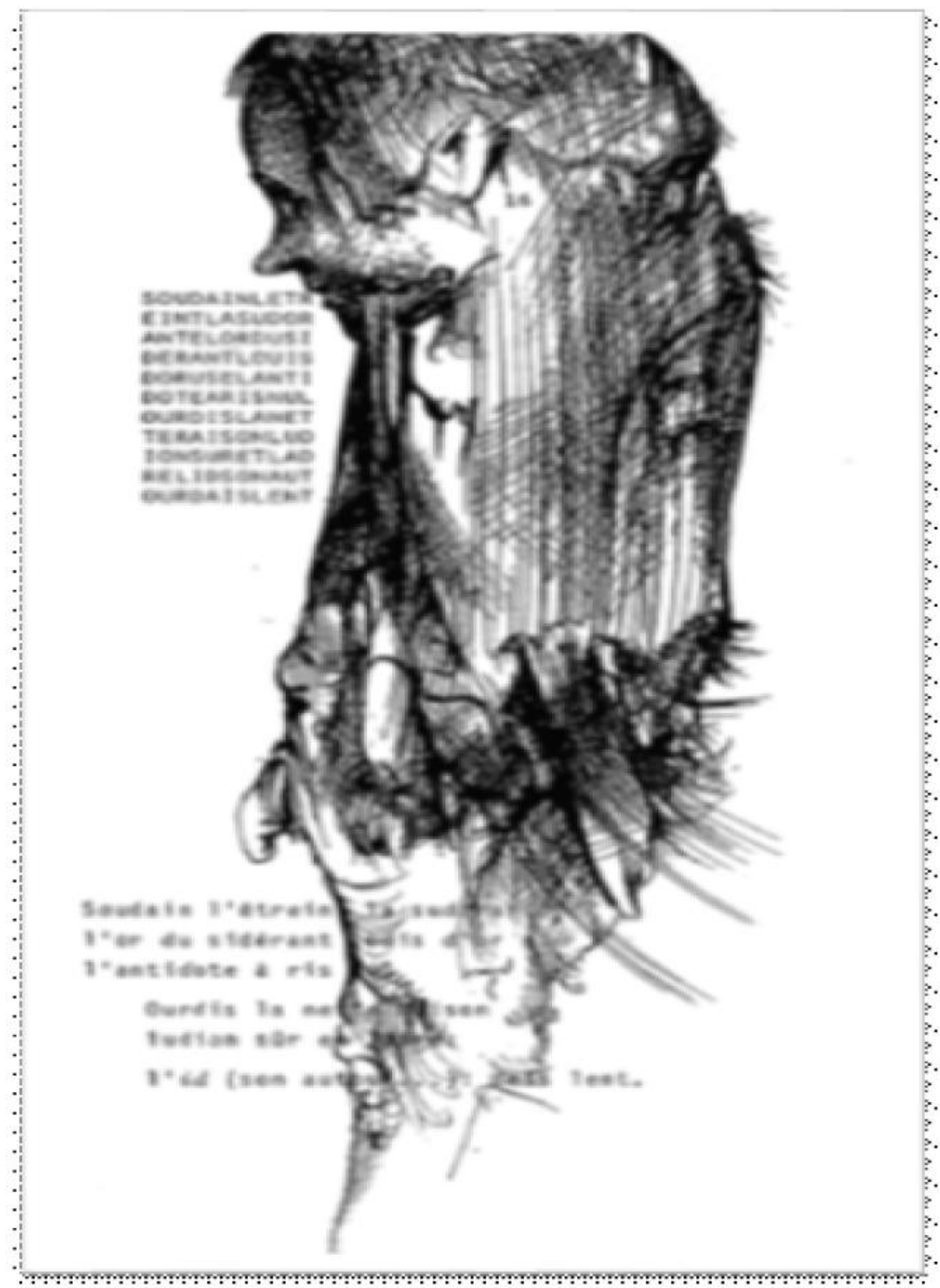

Figura 1 - Página de Alphabets, com ilustração de Dado. (Georges Perec Images, p. 145)

Com o artista Cuchi White criou a obra Trompe-l'oeil, onde tentou transpor ao texto a própria ideia do "trompe-l'oeil”, (ou seja, ilusão de ótica) se perguntando: “o que pode ser uma ilusão de ótica em um texto? Como podemos chegar à ideia da ilusão de ótica em um texto? Como podemos 
chegar à ideia da ilusão de ótica com palavras?" (p. 198). Assim, a escrita iniciada a partir das imagens resultará em uma reflexão sobre o seu próprio trabalho. Perec complementa sua questão, tentando talvez respondê-la: “se eu devo escrever um texto sobre a ilusão de ótica, eu não quero escrever um texto "sobre" Cuchi White, quero dizer, eu não vou também escrever um texto para dizer que as fotos são belas [...] é preciso que eu ache as fotos suficientemente belas para que elas me sirvam de trampolim, para que elas possam me fazer sonhar" (p. 200), ou seja: as imagens, segundo Perec, podem servir de motor para que seu trabalho apareça, sua imaginação corra, que haja essa escrita a partir do sonho, da viagem, estimulada por essas imagens. Como trazer para o próprio trabalho aquilo que está no trabalho do outro? A partir da imaginação, da observação, do trabalho conjunto, da percepção, da sensibilidade.

É interessante pensar naquilo que Pascal Quignard escreve, em seus Petits Traités, quando reflete sobre a interação entre imagem e escrita, ou entre artistas de "meios" diferentes: "Literatura e imagem são imiscíveis. Muitos são os pintores e os escritores que tentaram unir essas duas expressões. São apenas erros, assim como motivos para risos. Pretensão de loucos. Essas duas expressões não podem ser justapostas" (1997, p. 134).

Não podemos afirmar que o trabalho de Perec buscasse essa justaposição “impossível” pensada por Quignard. Vemos que seu trabalho caminha paralelamente àqueles dos artistas envolvidos, sem que um se justaponha ou prevaleça em relação ao outro; pelo contrário: há um movimento artístico que permite diálogos capazes de "ampliar" os horizontes - trazendo, para ambos, inestimáveis aprendizagens artísticas -, como dito por Barthes (1961, p. 1129) nesse curtíssimo trecho: "antes havia redução do texto à imagem, hoje há amplificação de um em relação ao outro”.

Uma das possíveis respostas a que chega, em relação aos trabalhos em parceria - é que deve tentar fazer em seu próprio trabalho “alguma coisa que venha se colar àquilo que ele [o outro artista] faz, mas que não é um comentário [...] como se o texto pudesse tentar ser o espelho da pintura" (p. 199).

Essa ideia de espelho da pintura fica muito clara quando nos dá o exemplo do último pintor com quem trabalhou: com Fabrizio Clerici, seu 
trabalho de escrita parece realmente um "reflexo" daquilo que aparece nos desenhos, tanto na ideia apresentada quanto na execução do trabalho. Vejamos o exemplo explicado pelo próprio Perec; segundo ele, o trabalho de Fabrizio tratava-se de:

(...) oito desenhos que são divididos em faixas longitudinais e que... cada desenho pode se combinar, é combinatório, pode se combinar com os outros, com cada parte do desenho [...] o que faz com que com oito desenhos pode-se obter [...] exatamente quatro mil e noventa e seis [...] (p. 199)

Surpreendentemente, quando diz qual foi o seu trabalho de escrita realizado a partir desses desenhos, inevitavelmente associamos a ele a ideia do espelho: "E então fiz textos que são quatro mil pequenos contos, quatro mil poemas em prosa que são baseados... fundados sobre oito mini-matrizes". (p. 199)

O último trabalho de parceria (que afirmara anteriormente ter sido com Fabrizio), foi de fato realizado com Pierre Getzler (a quem dedica seu livro de 1974, Espèces d'espaces), e sobre o qual afirma: "tenho a impressão que tudo que ele faz no seu trabalho encontra um eco em tudo que eu faço na minha escrita, e vice-versa: o que escrevo encontra um eco na sua pintura" (p.199), nos trazendo mais uma vez a ideia do espelho, do reflexo, do eco: interrelações entre a escrita e a imagem, em trabalhos de ambos os artistas.

Perguntado sobre as razões que motivariam esses trabalhos em parceria, Perec nos demonstra toda sua sensibilidade artística, ao relacionar seus trabalhos com os artistas a um desejo de beleza, a partir, por exemplo, do trabalho de construção do livro (passo a passo), o qual ele chama de "objeto belo"; esse objeto seria, então, uma das motivações para que ele fizesse parte desses projetos artísticos:

Nesse mundo há uma coisa muito reconfortante, que é ter a possibilidade, com meios um tanto limitados, de fabricar belos objetos. E eu chamo um belo objeto, ou seja, um livro que se fabrica do começo ao fim, o qual escolhemos o papel, o qual escolhemos as letras, trabalhamos com um tipógrafo, supervisionamos a tiragem das fotos, a configuração da página, escolhemos a 
encadernação. Tudo isso vai terminar com um objeto que é belo. [...] (p. 203)

Christelle Reggiani, no artigo "L'image perecquienne comme antitexte" (REGGIANI, 1988, p. 21-29) afirma que, na obra de Perec, a ligação entre textos e imagens não será mera ilustração, mas “uma relação estrutural no plano da atividade produtiva", ou seja, Reggiani nos explica que as contraintes de escrita tiram sua motivação das próprias imagens, ou seja, a motivação ou a produção da escrita nessas parcerias deve-se, portanto, à motivação anterior criada em Perec pelas próprias imagens manipuladas, a partir das quais pôde sonhar, imaginar, escrever.

De maneira similar, Márcia Arbex define o trabalho de colaboração de Robbe-Grillet com outros artistas: "não se trata, nesses trabalhos de colaboração, da ilustração do texto pela imagem, ou vice-versa, mas, antes, do trabalho de imaginação". (ARBEX, 2013, p. 23)

Não por acaso, ao comentar seu próprio trabalho na mesma conferência, afirmou: "je ne suis absolument pas critique d'art", ("não sou absolutamente crítico de arte") frase que usa no início de sua fala: como já mencionado, Perec não se utiliza de imagens para compor comentário a respeito delas, não quer ter um papel de crítico de arte: ao contrário, quer apropriar-se dessa arte ou incluí-la na sua própria, a arte de escrever.

\section{As imagens no texto/ o texto nas imagens}

Se fôssemos evocar todas as imagens relevantes presentes no texto de Perec, isso implicaria numa difícil empreitada: um único texto seria incapaz de dar conta de tantas imagens repetidas, frequentes, evidentes que se escondem no "labirinto" composto pela vasta obra do autor. Percorrendo brevemente algumas dessas imagens relevantes inseridas no texto, privilegiaremos evocar aquelas que consideramos "motores de escrita" para Perec.

Voltemos a 1978: Perec torna-se exclusivamente escritor (antes disso, conciliava seu trabalho de documentalista no CNRS, durante quase vinte anos, com seus projetos literários) a partir do sucesso de La Vie mode d'emploi. 
Antes disso, já em 1974, seu livro Espèces d'Espaces reuniu simultaneamente ensaios e uma escrita quase poética sobre diversos aspectos relativos ao espaço - desde sua cama até o país onde vive, o mundo - Perec comenta um dos seus projetos em andamento: La vie mode d'emploi parte desse questionamento, entre outras obras, sobre o espaço em que vivemos.

Discutir a presença de imagens nessa obra volumosa seria uma tarefa, senão impossível, de proporções não cabíveis nesse breve texto. Mas um dos aspectos cruciais aqui é justamente enfatizar a importância das imagens em relação à concepção do projeto. Perec afirma ter como uma das fontes um desenho de Saul Steinberg, que representa um prédio todo mobiliado, mas sem as paredes externas, o que possibilita que se tenha uma visão do que acontece "por dentro" da vida de cada uma das pessoas que ali vivem, dentro de seu apartamento, em seu cômodo específico, naquele exato momento.

É como se essa imagem fixasse um "plano de fundo" para a composição do projeto, a partir da observação e descrição de detalhes minuciosos desse microuniverso criado por Steinberg - visualmente - e que será de extrema importância para a criação literária de Perec:

As fontes desse projeto são múltiplas. Uma dentre elas é um desenho de Saul Steinberg, presente em The Art of Living, (Londres, Hamish Hamilton, 1952), que representa um imóvel [...] que teve uma parte da fachada retirada, deixando à mostra o interior de uns vinte e três cômodos. (PEREC, 1992, p.58) 


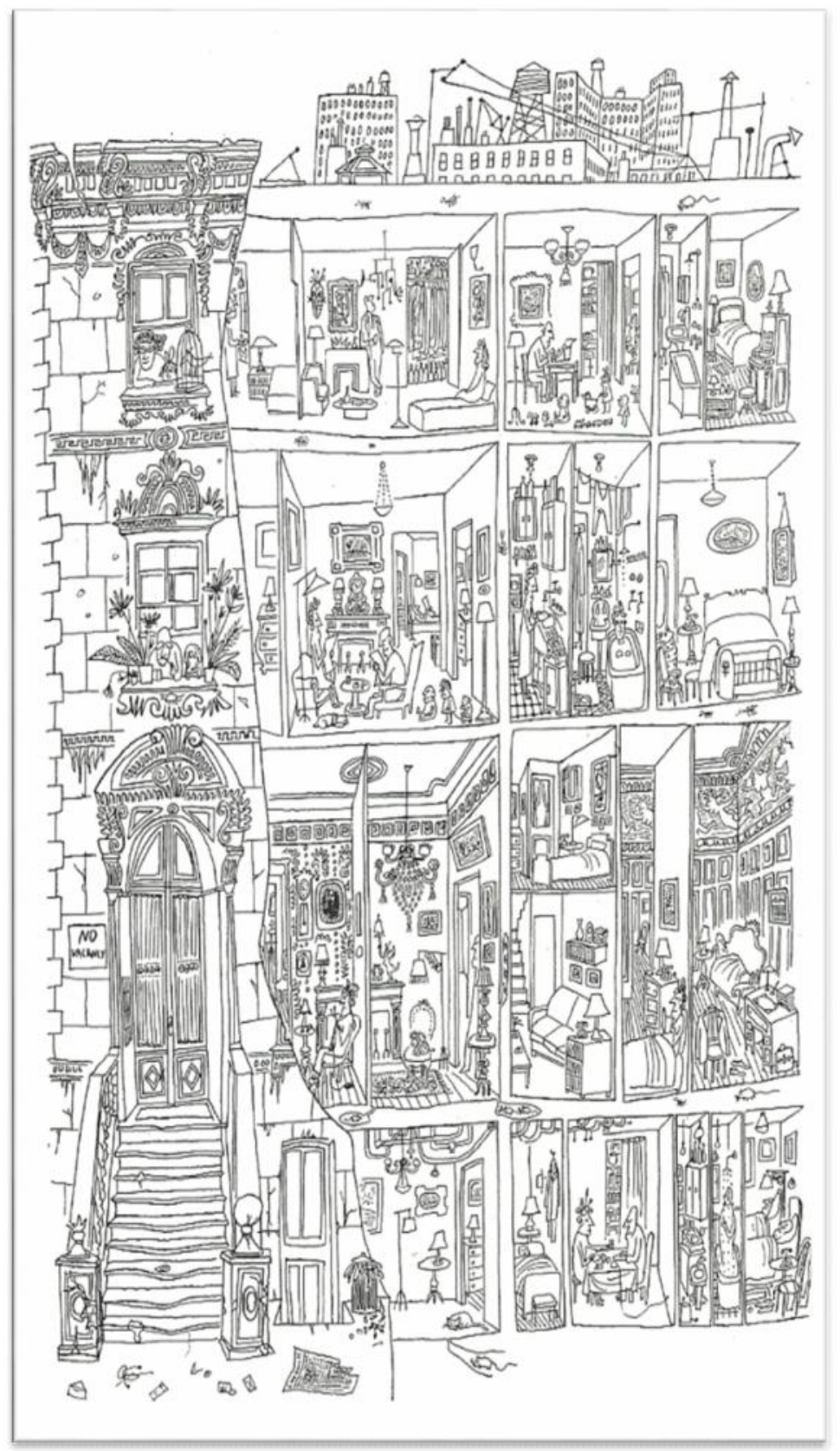

Figura 2 - The art of living, de Saul Steinberg. (Georges Perec Images, p. 150) 
Esse desejo de "esmiuçar", detalhar, observar imagens, que seriam os pontos de partida para a escrita, para o trabalho literário, estará presente em diversos momentos na obra de Perec, como veremos. Essa maneira de "enumerar" as coisas, será também "influência" da arte de Steinberg? Segundo Barthes ${ }^{4}$, essa enumeração de objetos presente na obra de Steinberg, "na qual não se deve buscar nenhuma ordem, nenhuma estrutura", será capaz de "designar o "mundo" - o mundo humano, urbano, que "me bombardeia" com suas imagens, suas repetições, seus artifícios".

Declarada a importância que Perec atribuía ao desenho de Steinberg, impossível não associar aos dois artistas as mesmas inquietações encontradas, um no desenho e o outro na escrita. Assim como Barthes afirma que Steinberg enumera o mundo mais ou menos como faria um enciclopedista, Perec afirma que desejaria encontrar em sua obra essa espécie de "totalidade do mundo", a partir de quatro grandes interrogações que vai se colocar, como veremos abaixo. É claro que muitas de suas obras perpassam entre uma ou mais dessas "categorias", mas seu objetivo parece quase enciclopédico, englobando tantos gêneros e interrogações a partir de diversos projetos literários simultâneos:

A primeira dessas interrogações pode ser qualificada de "sociológica": como olhar o cotidiano [...]; a segunda é de ordem autobiográfica[...]; a terceira, lúdica, remete a meu gosto pelas regras [...]; a quarta, enfim, diz respeito ao romanesco, o gosto pelas histórias e peripécias. (PEREC, 1985, p. 10)

Pensando na questão da imagem em relação à escrita, a pergunta que se coloca é: até que ponto esses pequenos detalhes apresentados no desenho poderão orientá-lo em busca de sua escrita "ideal"? Quanto mais detalhes, melhor? É o que podemos observar quando continua a descrever seu projeto de La vie mode d'emploi, em Espèces d'Espaces.

Um exame um pouco mais atento do desenho permitiria facilmente traçar detalhes de um romance volumoso: é evidente, por exemplo, que nos encontramos em uma época onde a moda é dos cabelos cacheados (três

\footnotetext{
${ }^{4}$ No texto "All except you - Saul Steinberg", em Inéditos -vol. 3- Imagem e moda, p. 187
} 
mulheres colocaram "bigoudis"), o homem que dorme sobre seu divã desconfortável é provavelmente um professor: é a ele que pertence a toalha de couro e ele tem no seu escritório alguma coisa que parece muito com um pacote de provas [...] (PEREC, 1992, p. 61)

Por isso, essa obsessão por observar, anotar, listar, investigar e, a partir daí, compor imagens do cotidiano, são questionamentos aos quais se coloca frequentemente: o espaço, o cotidiano, são as possíveis tentativas de ligar-se a algum lugar, tentar não se sentir tão estrangeiro quanto se sente - na maior parte do tempo - tendo em vista que boa parte de sua obra trata, mesmo que indiretamente, de questões ligadas à busca da própria identidade.

Segundo Perec, essa importância dada à observação das imagens do cotidiano surge a partir de uma descrição de coisas que já não enxergamos, já que tão habituados a tais imagens, como explica o autor, em entrevista publicada na revista $L^{\prime} A r C^{5}$ :

"Minha "sociologia" do cotidiano não é uma análise, mas somente uma descrição e, mais precisamente, descrição do que não olhamos jamais porque estamos nele, ou achamos que estamos, tão habituados e sobre o qual normalmente não há discurso" (PEREC, 1990, p. 4).

Outros exemplos de experiências de escrita inovadora podem ser aqui apresentados, (que carregam em si também imagens da vida cotidiana); uma delas é aquela em que participa de um projeto para uma rede de televisão - programa intitulado La vie filmée des français (Figura 3) - para o qual Perec escreveu os comentários, a partir de imagens antigas, do bairro onde passou sua infância, comentadas por ele no texto Le travail de la mémoire ${ }^{6}$ : “Trabalhei então com documentos onde quase encontrei minha própria história. Um desses filmes se passava no meu bairro de infância e era como se eu estivesse com minha mãe, meus pais, na imagem!" (PEREC, 1990, p. 81)

\footnotetext{
${ }^{5}$ Entrevista concedida a Jean-Marie Le Sidaner e publicada em 1990.

${ }^{6}$ Publicado em Je suis né, em 1990, p. 81. (Mais detalhes sobre o documentário, além da transcrição dos comentários de Perec - feita por Cécile de Bary, incluindo alterações posteriores feitas no texto pelo próprio Perec -, podem ser encontrados no texto La vie filmée, em “Cahiers Georges Perec 9", Le Castor Astral, 2006, p. 73-82).
} 
Interessante pensar na importância da imagem para reconstruir um espaço, mesmo que seja um espaço de convivência (fictício) do qual não fez parte, mas a partir do qual pôde desenvolver sua escrita.

A partir de imagens antigas, que remetem a um tempo remoto, em um acontecimento não vivido por ele, (mas talvez por seus pais, mesmo que nada se saiba a respeito), Perec elabora um texto que servirá de comentário a essas imagens que não lhe "pertencem", diretamente, mas que fazem parte de uma memória coletiva, transformada por ele em uma "possível memória familiar".

Esse será exatamente o mesmo movimento de escrita presente na obra Récits d'Ellis Island: a partir de imagens de desconhecidos, que viveram em uma outra época, é possível escrever uma autobiografia "provável", investigar a História do outro para construir sua própria história, hipoteticamente criada, a partir da escrita e imaginação, já que a autobiografia "própria" não encontra maneiras para ser representada, há uma "impossibilidade de escrita" a respeito dela.

Vemos, portanto, momentos distintos e situações totalmente adversas em que surgem oportunidades para que o texto literário venha à tona, se relacione com essas imagens, interfira no cotidiano a partir delas.

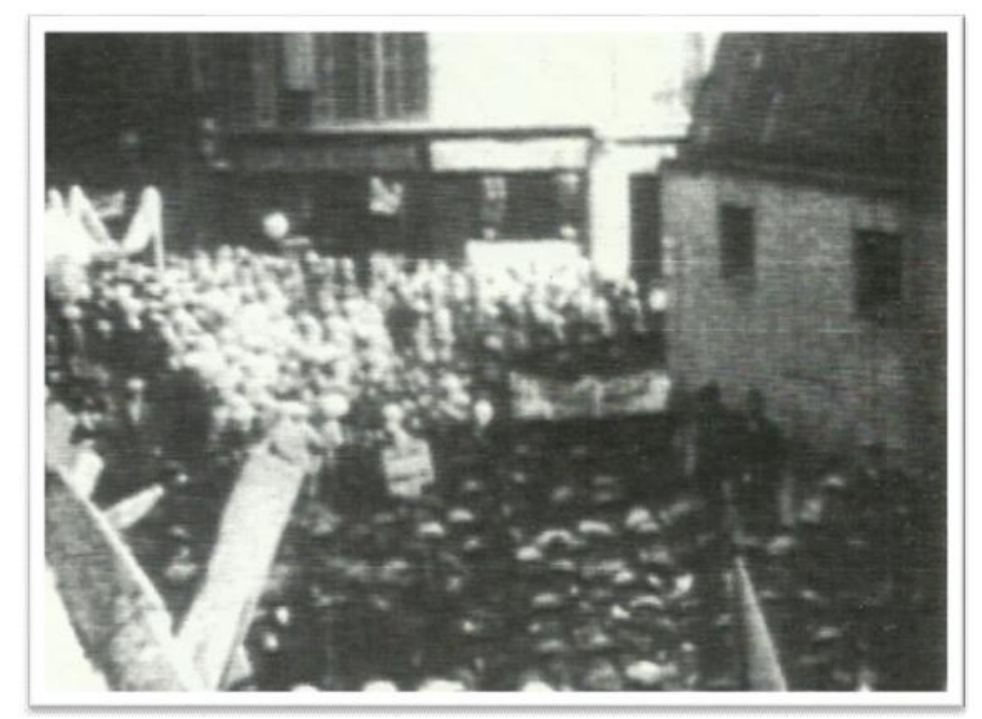

Figura 3 - Imagem do documentário LA VIE FILMÉE DES FRANÇAIS. (Georges Perec Images, p. 27) 
Outro exemplo de uso inesperado de imagens refere-se a uma foto entregue a Perec, da qual ele se valerá para a escrita de um capítulo de La Vie mode d'emploi: “Um dia me ofereceram uma fotografia de um filme de Marcel L'Herbier, e no dia seguinte, me servi dela para um dos capítulos de La Vie mode d'emploi e seu presente tornou-se a fonte de uma história, de alguma coisa que chegou antes". (PEREC, 1990, p. 91-92)

Vemos a seguir o manuscrito e o texto passado a limpo: a partir da descrição inicial da personagem, vejo que houve um trabalho de escrita "incentivado" por essa bela mulher ("une américaine énigmatique”) presente na foto, conforme a transcrição abaixo (seguida da reprodução dos manuscritos) do texto escrito para o capítulo LXV de La Vie mode d'emploi:

\begin{abstract}
QUARTA PARTE
Capítulo LXV

Moreau, 3

No início dos anos cinquenta, viveu no apartamento que a senhora Moreau mais tarde adquiriu uma americana enigmática, a qual, por causa de sua beleza, de seus cabelos louros e do mistério que a envolvia, foi apelidada Lorelei. Dizia chamar-se Joy Slowburn e aparentemente morava sozinha naquele imenso espaço sob a proteção silenciosa de um motorista e guarda-costas chamado Carlos, um filipino baixinho e espadaúdo, sempre irrepreensivelmente vestido de branco. Era encontrado às vezes nas lojas de artigos de luxo, adquirindo frutos confeitados, chocolates ou guloseimas. Mas ela jamais era vista na rua. As persianas estavam sempre fechadas; não recebia correio, e sua porta se abria apenas para os entregadores que lhe traziam refeições já preparadas ou para os floristas que, todas as manhãs, portavam grandes braçadas de lírios, áruns e tuberosas. Joy Slowburn só saía tarde da noite, conduzida por Carlos num enorme Pontiac negro. As pessoas do prédio viam-na passar, estonteante, em seu vestido comprido de faille de seda branca de cauda longa que deixava as costas quase nuas, uma estola de visom no braço, com um grande leque de plumas negras e cabelos de um louro sem igual [...] (PEREC, 1991, p. 317)
\end{abstract}


A partir dessa descrição, e observando a foto abaixo (Figura 4), podemos confirmar que essa imagem foi essencial na produção da escrita literária desse trecho da obra, já que funcionou como motor de escrita para Perec:

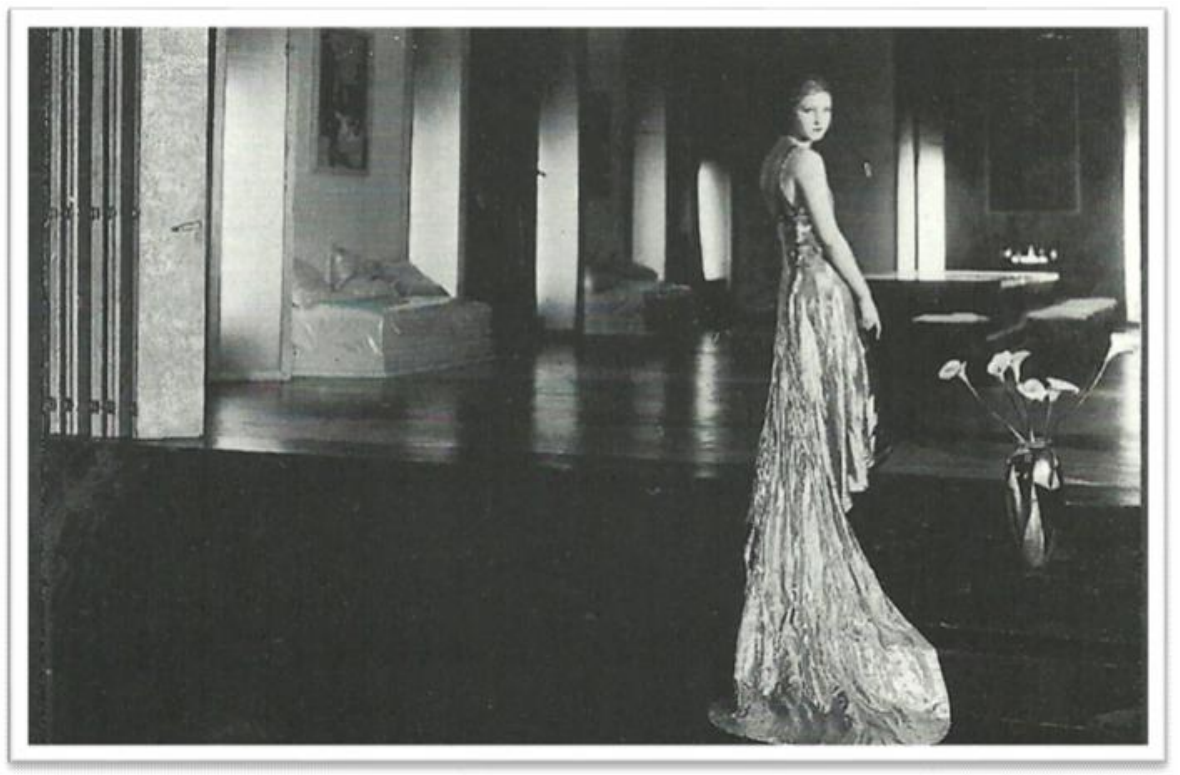

Figura 4 - Brigitte Helm no filme "L'argent”, de Marcel L'Herbier, que “inspirou” a persongagem de La vie mode d'emploi. (Georges Perec Images, p. 155)

Temos a seguir a reprodução do manuscrito, ao lado do texto passado a limpo: a partir da descrição inicial da personagem, podemos perceber que houve um trabalho de escrita "incentivado" por essa bela mulher ("une américaine énigmatique") presente na foto, conforme a transcrição abaixo (seguida da reprodução dos manuscritos) do texto escrito para o capítulo LXV de La Vie mode d'emploi: 


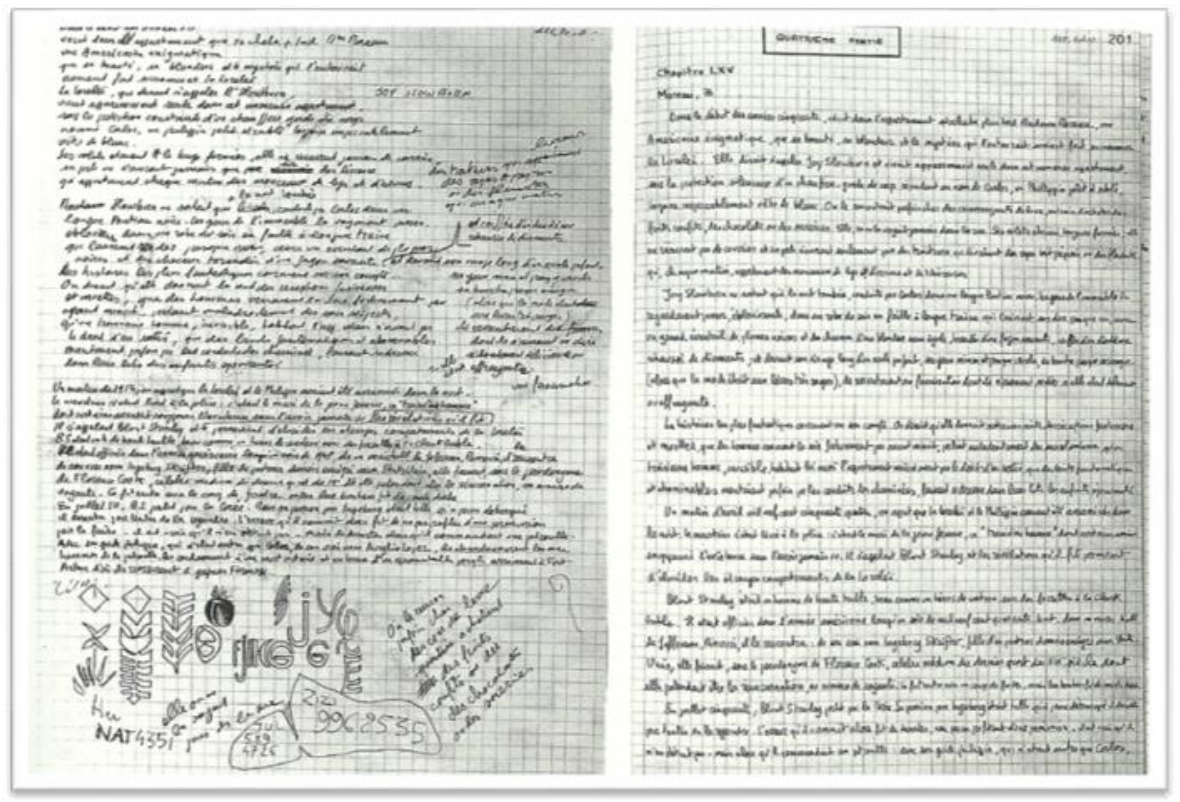

Figura 5 - Manuscrito original e cópia passada a limpo do início do capítulo LXV de La vie mode d'emploi. (Georges Perec Images, p. 155)

Além do comentário citado acima, onde indica ter se "inspirado" na foto para criar uma personagem em La vie mode d'emploi, vemos que, a partir da descrição, o autor novamente vai se valer da minúcia de detalhes para constituir seu trabalho de escrita. As roupas descritas, o ambiente, as flores, somente observados na imagem funcionam como "ponto de partida" para enriquecer sua narrativa.

A partir da observação da roupa na foto, imagina uma personagem misteriosa, que só sai de casa à noite, quando não pode ser vista. A partir do vaso de flores, imagina a personagem recebendo-as em casa por um florista, a cada manhã. São detalhes que vão sendo acrescentados à narrativa, a partir de uma imagem e tudo que ela pode suscitar, no sentido de estimular a imaginação e a escrita. Além das fotografias e ilustrações apresentadas até aqui, não podemos deixar de ressaltar também a pintura como uma fonte constante de inspiração para a escrita de Perec, como veremos a seguir. 


\section{Portrait d'un homme, ou a história de uma cicatriz}

Novamente veremos as relações entre escrita, espaço e imagem, a partir descrição do quadro Saint Jerôme dans son cabinet de travail, em Espèces d'Espaces: a partir de minúcias e detalhes, temos uma descrição exaustiva de Saint Jerôme, em seu local de trabalho: um móvel de madeira instalado em uma igreja; espécie de escrivaninha, que concentra todas as inquietações do processo de escrita: ao mesmo tempo em que há a descrição de objetos, há a reflexão sobre o espaço e também sobre o ato de escrever. O início do texto indica uma composição descritiva do texto, ao mesmo tempo em que mostra Saint Jerôme em plena atividade de leitura/trabalho:

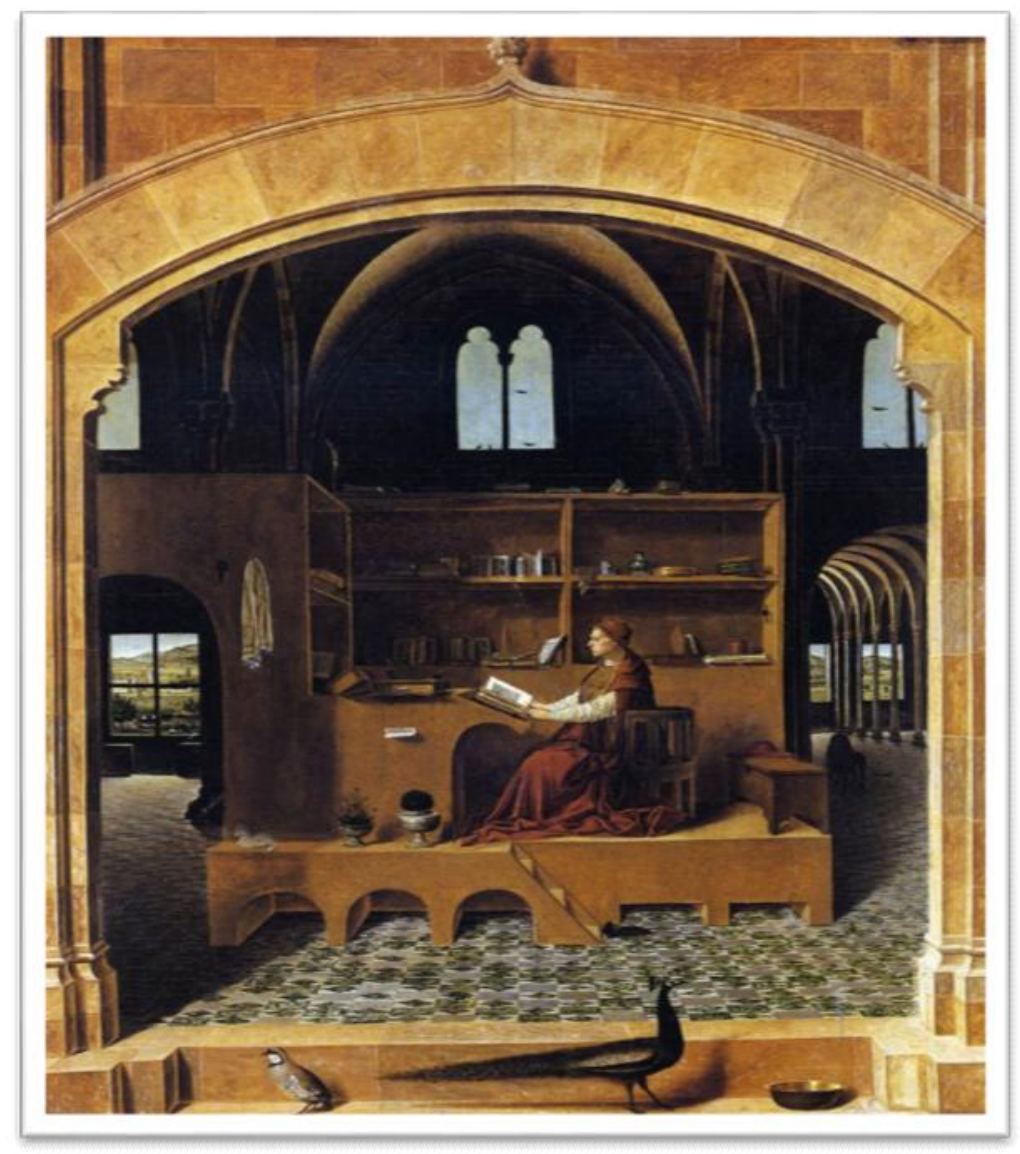

Figura 6 - Saint Jerôme dans son cabinet de travail 
O gabinete de trabalho é um móvel de madeira colocado sobre os azulejos de uma catedral. Ele fica sobre uma plataforma que se acessa por três passos, e compreende principalmente seis armários cheios de livros e de diversos objetos (sobretudo caixas e um vaso), e uma mesa de trabalho cuja parte plana suporta dois livros, um tinteiro e uma pluma, e a parte inclinada o livro que o santo está lendo. (PEREC, 1992, p. 117)

Esgotadas as possibilidades de descrição do móvel, a visão se amplia, nos dando também um panorama do entorno do móvel, ou seja, o espaço onde está inserido, já no final do texto:

\begin{abstract}
O espaço inteiro se organiza em torno desse móvel (e o móvel inteiro se organiza em torno do livro): a arquitetura glacial da igreja (a nudez dos azulejos, a hostilidade de seus pilares) se anula: suas perspectivas e verticais deixam de delimitar o único lugar de uma fé inefável; elas estão ali mais para dar ao móvel sua escala, permiti-lo inscrever-se. no meio do inabitável, o móvel define um espaço doméstico que os gatos, os livros e os homens habitam com serenidade. (PEREC, 1992, p. 118)
\end{abstract}

Assim como Perec faz o movimento de inter-relações do espaço entre todas as seções do livro, desde o espaço da cama, do quarto, do apartamento e assim por diante, até chegar ao universo, esse movimento se repete na composição desse curto texto, a partir da observação do quadro: primeiro descreve o móvel, seus objetos, afirma que o espaço se organiza em torno do móvel, depois caminha para a dimensão espacial da igreja para, finalmente, dizer que o móvel inteiro se organiza em torno do livro.

Dentro desse constante movimento de ir e vir, observar as imagens será fundamental para produzir esse complexo movimento de escrita, desde os textos que vão compor o livro como um todo, até as seções que se interligam, transformando o livro num único todo: espaço, imagens, escrita, movimentos constantes e complementares.

Vale ressaltar também outro momento em que essa mesma imagem aparecerá: na primeira descrição do escritório de Sylvie e Jerôme, em $A s$ coisas. lá estariam presentes e descritos logo no início do texto, "algumas 
gravuras, desenhos, fotografias - o São Jerônimo de Antonello de Messina [...]" (PEREC, 1969, p. 12).

Todavia, apesar da importância e recorrência nessas obras, Saint Jerôme parece não ter superado outro quadro de Antonello de Messina: aquele intitulado Portrait d'un homme nos dá a impressão de ter sido uma das grandes imagens motivadoras da escrita para Perec, principalmente por encontrar nesse personagem grande identificação, já que ambos possuem a mesma cicatriz no lábio superior. Uma das menções que faz à obra, em seu texto de $W$ ou a memória da infância, funciona ao mesmo tempo com um relato de infância,

Um dia, um de meus esquis escapou das mãos e bateu de leve no rosto do rapaz que estava a meu lado guardando seus esquis e que, furioso, pegou um de seus bastões de esquiar e me desferiu um golpe no rosto com a ponta do bastão, abrindo-me o lábio superior [...] a cicatriz que resulta dessa agressão ainda hoje é perfeitamente visível [...] tornou-se uma marca pessoal, um sinal distintivo [...] (PEREC, 1995, p. 130)

e a relação desse acidente infantil com a preferência que dará a esse quadro, anos depois:

Foi essa cicatriz também que me fez preferir a todos os quadros reunidos no Louvre, e mais precisamente numa sala chamada "dos sete metros", o Retrato de um homem, dito $O$ Condottiere, de Antonello de Messina, que veio a ser a figura central do primeiro romance mais ou menos acabado que consegui escrever: ele se intitulou inicialmente Gaspard pas mort, depois Le Condottiere. (PEREC, 1995, p. 130) 


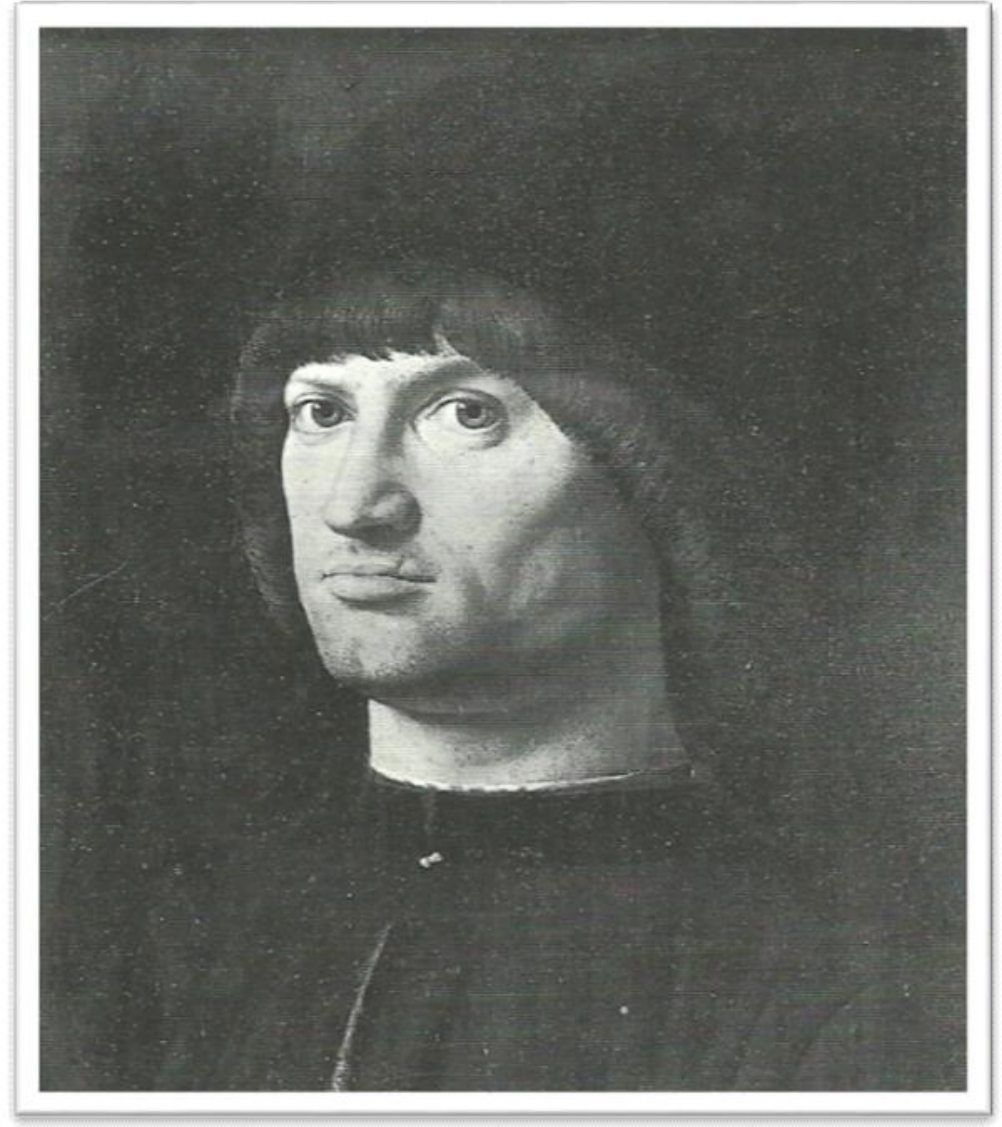

Figura 7 - Antonello da Messina, Le Condottiere. (Georges Perec Images, p. 61)

Essa relação de identidade (mesmo que o motivo dessa suposta “identidade" entre a imagem do quadro consigo mesmo seja decorrente de um acidente, e a cicatriz deixada por ele) é talvez o ponto de partida para a escrita do livro que revela ser "seu primeiro romance" inacabado.

Veremos outros exemplos em que essa imagem reaparecerá, uma delas é sem dúvida no livro Un homme qui dort. nesse trecho voltará à cena do museu do Louvre, no momento de contemplação da obra:

Você olha os jogadores de cartas nos jardins do Luxemburgo, as grandes águas do Palácio de Chaillot, vai ao Louvre no domingo, atravessando sem parar todas as salas, parando perto de um único quadro ou de um único 
objeto: o retrato incrivelmente enérgico de um homem da Renascença, com uma pequena cicatriz acima do lábio superior, à esquerda, ou seja, à esquerda para ele, à direita para você. [...] (PEREC, 1993, p. 92-93)

$\mathrm{Na}$ adaptação homônima dessa obra para o cinema, uma curiosidade: coincidentemente, o ator escolhido para o papel também apresentava uma cicatriz no lábio superior, semelhante tanto à de Perec quanto à do homem retratado no quadro.

$\mathrm{Na}$ cena do filme reproduzida na imagem abaixo (Figura 8), vemos ao fundo uma espécie de mise en abîme: lá está o quadro Portrait d'un homme, novamente, nos observando e sendo observado por nós.

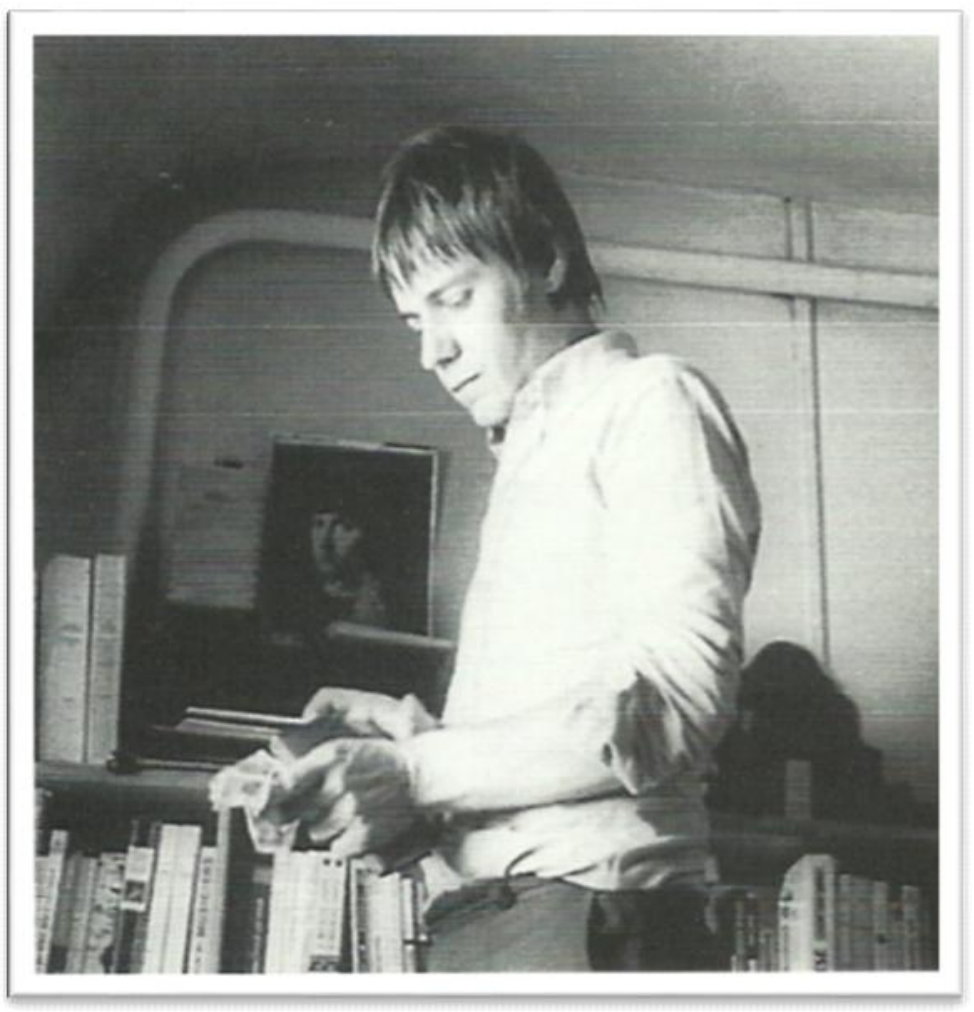

Figura 8 - Cena do filme Un homme qui dort, com o quadro de Antonello da Messina ao fundo. 
Em seu texto Perec, Simon et le Condottiere, Brigitte FerratoCombe (1998, p.103) diz constatar, a partir da leitura de Bernard Magné: "as ressonâncias autobiográficas do retrato à cicatriz [...] são sempre ligadas aos episódios disfóricos marcados pela quebra, pela separação: solidão quase autista do personagem em Um homem que dorme, dentes quebrados e lábio cortado em $W[\ldots] "$

Se há uma possível ligação ou identidade entre quadro e o autobiógrafo Perec (nesse caso, aquele de Wou a memória da infância), essa é uma identidade marcada pelo acidente, fissura, quebra, separação.

Já que não há ligação, identidade, cria-se essa identidade a partir de uma mutilação sofrida, como se ambos compartilhassem de determinada perda, mutilação, agressão, ou seja, ainda segundo Ferrato-Combe, “a cicatriz é somente o signo aparente de uma ferida bem mais profunda e a lembrança da agressão no esqui a tela de uma realidade mais mutiladora, aquela da separação e da morte".

Assim, as falhas deixadas pela cicatriz podem ser também as falhas da identidade, da memória. Esse detalhe, captado pela observação de Perec, fez-se constituir no sentimento de identidade que perpassa sua escrita, sempre que se refere à imagem desse homem sem nome, somente representado a partir de seu portrait.

\section{Considerações finais}

Para encerrarmos nossa reflexão, apresentamos brevemente um trecho escrito por Perec em mais uma de suas empreitadas "fora" da literatura: em um projeto para uma série radiofônica ${ }^{7}$, escreveu sobre aquilo que ainda pretendia fazer antes de morrer, versão escrita de uma participação na série de Jacques Bens, chamada Les 50 choses que je voudrais faire avant de mourir (As 50 coisas que eu gostaria de fazer antes de morrer). Entre as 37 enumerações que faz (decide parar na 37 e não ir até a 50), cita alguns projetos desejados para o futuro, mas que dependiam de outros artistas para serem realizados; duas delas me chamaram a atenção, justamente por se

\footnotetext{
${ }^{7}$ Reproduzido em Je suis né, p. 108, sob o título "Quelques-unes des choses qu'il faudrait tout de même que je fasse avant de mourir".
} 
relacionarem com outras artes, bastante mencionadas até aqui: "escrever um roteiro de filme de aventuras" e "trabalhar com um desenhista de HQ".

Ao ler sobre esse último projeto, reafirmamos a importância das imagens em relação ao texto para Perec: ao revelar o desejo de trabalhar com um ilustrador de quadrinhos, talvez tenha se esquecido ou não tenha dado importância ao que realizou, ainda no Lycée Henri-IV (em 1954-55): uma história em quadrinhos, singela, com um dos colegas de sala, Bernard Quilliet, e com a qual verificamos que, de certa forma, as imagens sempre estiveram presentes em seu trabalho literário, ainda que o próprio autor não se lembrasse mais delas ao enumerar seus desejos ainda não realizados:

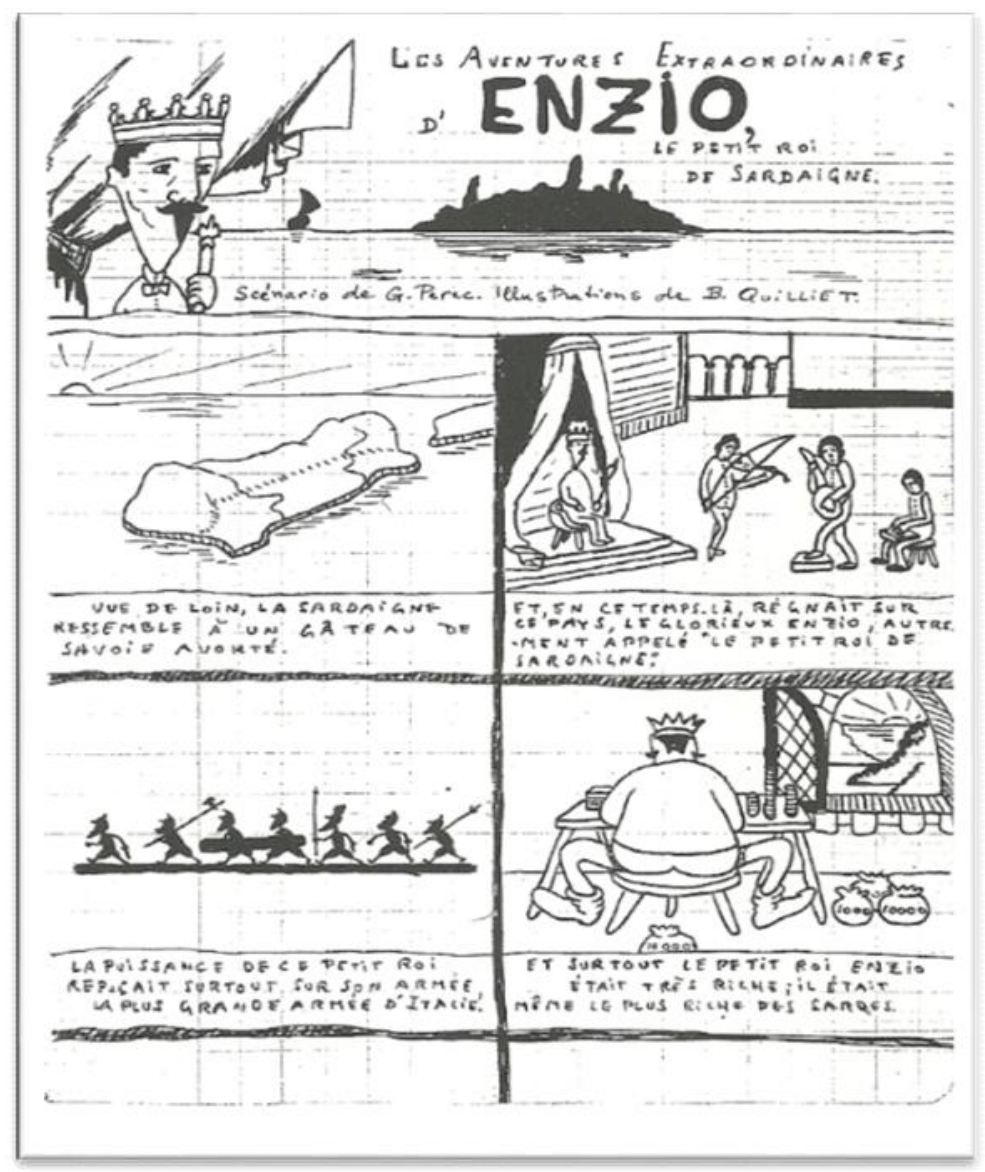

Figura 9 - Les aventures extraordinaires d'Enzio, le petit roi de Sardaigne. (Georges Perec Images, p. 47) 
Podemos imaginar que essa experiência não tenha sido muito relevante para o próprio autor, caso contrário ele se lembraria de tê-lo realizado, ou na hipótese de lembrar-se dele, talvez o considerasse um trabalho "amador", que precisasse ainda se desenvolver de maneira mais consistente.

Para nós, pesquisadores, pelo contrário, ver um trabalho de parceria de Perec com um ilustrador, muito antes de que imaginasse fazer algum sucesso como escritor, nos dá ainda mais certeza de que todas as suas parcerias sempre fizeram parte de sua trajetória como artista, independente da relevância do trabalho: já no título da história, - Les aventures extraordinaires d'Enzio - le petit roi de Sardaigne - (As aventuras extraordinárias de Enzio - o pequeno rei de Sardaigne) o autor nos mostra seu gosto por narrativas de aventuras, algo que também afirma ao longo de toda a sua carreira.

Além disso, é curioso também verificar que o primeiro quadrinho começa com um desenho de um mapa, que mostra a terra de Sardaigne, "vista de longe"; e ela tem a aparência de uma ilha. Inevitável não relacionar esse trabalho ainda "amador", às ilhas posteriormente descritas e narradas por Perec: a ilha de W ou a memória da infância, ficcional, ou a ilha Ellis Island, real, ambas fazendo importantes relações com questões autobiográficas no texto perecquiano, questões essas que se refletem, de maneira geral, por toda a obra do autor.

Destacamos apenas as duas últimas por serem obras que realizarão de maneiras distintas a intersecção entre texto literário e fotografia: em linhas gerais, podemos dizer que em Wou a memória da infância Perec se vale de fotografias antigas para escrever um texto autobiográfico a partir dessas fotos, tendo em vista que afirma, logo no início do texto, não possuir "nenhuma memória da infância". Assim, o autor escreverá uma espécie de autobiografia "ficcional”, já que descreve as fotos e "recria” cenas e memórias de sua infância que não lhe pertencem. Já em Récits d'Ellis Island, Perec manipula fotos de desconhecidos e, a partir delas, conta uma autobiografia "provável”, ou seja, a partir da memória dos outros cria uma história que "poderia ter sido" a sua. 
Outro aspecto a ser observado nas duas obras é que em $W$ não há a reprodução das fotos, fazendo com que o leitor "crie" suas próprias imagens. Em Récits d'Ellis Island, todavia, o texto aparece em meio às fotografias, como em um álbum de família, mesmo que não haja ali nenhum rosto conhecido. Em parceria com Robert Bober, o resultado desse trabalho será um livro com fotografias e um documentário, onde novamente essas fotos serão manipuladas.

Portanto, independentemente da maneira como lida com as imagens ou fotografias, o que parece fundamental é a produção literária criada a partir da observação e manipulação dessas imagens e o resultado final, em todas as obras aqui apresentadas, nos mostra a oportunidade de verificar quão produtivas foram essas parcerias, trazendo para os leitores de Perec novas experiências de leitura e novas apreciações artísticas, amplificando mutuamente os textos e as imagens em questão.

\section{Referências}

ARBEX, Márcia. Alain Robbe-Grillet e a pintura. Jogos Especulares. Belo Horizonte: EdUFMG, 2013.

BARTHES, Roland. All except you - Saul Steinberg. In: Inéditos - vol. 3Imagem e moda. São Paulo: Martins Fontes, 2005.

BARY, Cécile de. (Org.). Cahiers Georges Perec 9. Le cinématographie. Pantin: Le Castor Astral, 2006.

BARY, Cécile de. Le message photographique. In: Oeuvres complètes (t.1). Paris: Seuil, 2002.

BEAUMATIN, Éric; HARTJE, Hans. (Org.).Cahiers Georges Perec 6. L'Oeil d'abord. Georges Perec et la peinture. Travaux réunis par Éric Beaumatin et Hans Hartje. Paris: Seuil,1996.

FERRATO-COMBE, Brigitte. Perec, Simon et le Condottiere. In: Le Cabinet d'amateur. Perec et l'image, Toulouse, n. 7-8, 1998. p. 99-106.

NEEFS, Jacques; HARTJE, Hans. Georges Perec: images. Paris: Seuil, 1993.

PEREC, Georges; LE SIDANER, Jean-Marie. Entretien. In: L'Arc. Librairie Duponchelle, n. 76, 1990. 
PEREC, Georges. A vida modo de usar: romances. São Paulo: Cia das Letras, 1991.

PEREC, Georges. As coisas: uma estória dos anos 60. São Paulo: Nova Crítica, 1969.

PEREC, Georges. Espèces d'espaces. Paris: Galilée, 1992.

PEREC, Georges. Je suis né. Paris: Seuil, 1990.

PEREC, Georges. La vie mode d' emploi: romans. Paris: Hachette, 1991.

PEREC, Georges. Les choses: une histoire des années soixante. Paris: Julliard, 1991.

PEREC, Georges. Penser, classer. Paris: Hachette, 1985.

PEREC, Georges. Un homme qui dort. Paris: Denoël, 1993.

PEREC, Georges. W ou le souvenir d'enfance. Paris: Denöel, 1975.

PEREC, Georges. Wou a memória da infância. São Paulo: Cia das Letras, 1995.

QUIGNARD, Pascal. Sur les rapports que le texte et l'image n'entretiennent pas. In: Petits Traités, v. 1. Paris: Gallimard, 1997.

REGGIANI, Christelle. L'image perecquienne comme antitexte. In: Le Cabinet d'amateur. Perec et l'image, Toulouse, n. 7-8, 1998. p. 21-29.

Recebido em 27 de abril de 2017.

Aceito em 06 de junho de 2017. 